\title{
Preface to the special issue "Induced seismicity: observations, monitoring, and risk management strategies"
}

\author{
Tony Alfredo Stabile • Antonio Pio Rinaldi • Kristine \\ Pankow
}

Received: 2 September 2020 / Accepted: 2 September 2020/Published online: 11 September 2020

(C) Springer Nature B.V. 2020

It is well known that industrial activities related to development and production of energy have the potential to induce minor seismicity or trigger larger earthquakes. This is a global phenomenon with implications for seismic hazard and risk, and real concern exists about larger earthquakes that might be triggered by industrial activities especially in densely populated areas. Public and regulatory concerns about the potential hazard from induced earthquakes continue to evolve in response to a deepening scientific understanding of the underlying mechanisms and improvements to probabilistic seismic hazard models. There is a growing understanding that taking steps to reduce the hazard can mitigate the risk. Consequently, guidelines for monitoring are being revised and improved.

This special issue principally gathers a selection of contributions presented at the Session S32 focused on induced seismicity of the 36th General Assembly of the European Seismological Commission held in Malta on 2-7 September 2018 and also additional contributions

Guest Editors: Tony Alfredo Stabile (IMAA-CNR, Italy), Antonio Pio Rinaldi (ETH, Switzerland), and Kristine Pankow (University of Utah, USA)

T. A. Stabile $(\bowtie)$

Consiglio Nazionale delle Ricerche, Istituto di Metodologie per

l'Analisi Ambientale, C.da S. Loja, Zona Ind.le, Tito Scalo,

85050 Potenza, Italy

e-mail: tony.stabile@imaa.cnr.it

A. P. Rinaldi

Schweizerischer Erdbebendienst (SED) ETH Zürich,

Sonneggstrasse 5, Building NO, Room H57, 8092 Zürich, from other researchers. The articles included in this special issue provide theoretical, experimental, and observational advances in detecting, monitoring, and understanding the seismicity induced by hydrocarbon exploitation, geothermal development, and other industrial operations, as well as hazard management strategies for reducing the risk, including monitoring guidelines and the implementation of traffic light systems.

Two manuscripts investigate the time dynamics of induced seismicity with advanced methodologies and robust statistics in order to find peculiar patterns of induced earthquakes or relationships between the observed seismicity and the anthropic perturbations:

- Skoumal et al. (2020) used template matching to enhance the earthquake catalog in the midContinental United States (Oklahoma and Southern Kansas) for the time period mid-2008 through 2016. Using this enhanced earthquake catalog of over 200,000 earthquakes, they found that seismicity

\author{
Switzerland \\ e-mail: antoniopio.rinaldi@sed.ethz.ch \\ K. Pankow \\ University of Utah, 115 South 1460 East, Salt Lake City, UT \\ 84112, USA \\ e-mail: pankowseis2@gmail.com
}


across the study area is swarm-like, they identified active foreshock sequences for four magnitude 5 and larger events, and by comparing the catalog to poroelastic stress models, they conclude that injection rate is a contributor to seismic hazard.

- Telesca et al. (2020) analyzed the relationships between the water level fluctuations of the Mingechevir reservoir (Azerbaijan) and the observed seismicity recorded nearby the lake between January 2010 and August 2018 by the RCSS-ANAS seismic network. The authors applied three robust time series analysis methods to identify a 12- to 13-month periodicity of seismicity which is compatible with the yearly periodicity of the reservoir water level.

Three papers provide theoretical, experimental, and observational advances in detecting and monitoring induced seismicity:

- De Landro et al. (2020) investigate the theoretical performances for different geometry and station density of seismic networks in terms of minimum magnitude detection and location errors. The analysis has been done by taking into account the performance standards required by the Italian government guideline (IGL) for the monitoring of the microseismicity in areas where industrial exploitation activities take place. The authors show that with the addition of a constellation of small-dimension seismic arrays, it is possible to achieve the network performances in terms of detection capability and location accuracy that are required by the IGL, and eventually to reach greater performances.

- Carannante et al. (2020) evaluated the detection improvement of the microseismic network, integrated with regional stations, for the storage concession "Minerbio Stoccaggio" (Italy). The authors calculated detection and location threshold for both an inner and external domain of detection (IDD and EDD, respectively). Results show that under unfavorable noise conditions, the seismic network is capable of locating earthquakes with $M_{L} \geq 0.8$ occurring at the depth of the reservoir and with $M_{L} \geq 1.0$ if located within IDD.

- Adinolfi et al. (2020) present an application of the coherence-based detection and location scheme to 1 year of continuous data recorded at the Iripinia Seismic Network (ISNet) in southern Italy. Such applications are important for improvement of monitoring seismically active regions and areas characterized by induced seismicity. Also, the multi-step procedure using different criteria presented in the paper is an interesting and potentially useful port-processing improvement of the coherence-based methods.

Two articles address the issue of the risk management strategies related to seismicity induced by industrial operations:

- Ader et al. (2020) give a comprehensive description of the design and implementation of a Traffic Light System (TLS) applied in the recent deep geothermal stimulation project in the Helsinki area, Finland. It is a timely contribution, providing technical details and reasons for using the specified TLS, which may find parallels in other ongoing/future fluid-injection projects.

- Braun et al. (2020) give a general overview about the application of the IGL for monitoring the activities carried out underground mainly for energy production. The authors describe first the framework in which the IGL was conceived and developed, and summarize the main concepts introduced. Then they report the sites where IGL are applied at experimental level and discuss the experience gained till now and the main critical issues of the current IGL, thus suggesting future revisions.

Finally, Lanzoni et al. (2020) focus on fast $M_{w}$ calculation of microseismic events recorded around the underground storage facility of Collalto (Italy) by a dedicated seismic monitoring network. The authors compute $M_{w}$ from the response spectra calculated at fixed periods (i.e., 1.0 and $0.3 \mathrm{~s}$ ) showing that the spectra and magnitude scale as $2 / 3$. Then they extend their method to microseismicity by using response spectra at $0.1 \mathrm{~s}$. The authors estimate $M_{w}$ for 1659 events, finding a $2 / 3$ scaling relationship between $M_{w}$ and $M_{L}$. The authors show that the applied routine is suitable for real-time monitoring, and it could be an asset for traffic light systems for management of induced seismicity.

\section{References}

Ader T, Chendorain M, Free M, Saarno T, Heikkinen P, Malin PE, Leary P, Kwiatek G, Dresen G, Bluemle F, Vuorinen T (2020) Design and implementation of a traffic light system 
for deep geothermal well stimulation in Finland. J Seismol. https://doi.org/10.1007/s10950-019-09853-y

Adinolfi GM, Picozzi M, Cesca S, Heimann S, Zollo A (2020) An application of coherence-based method for earthquake detection and microseismic monitoring (Irpinia fault system, Southern Italy). J Seismol. https://doi.org/10.1007/s10950020-09914-7

Braun T, Danesi S, Morelli A (2020) Application of monitoring guidelines to induced seismicity in Italy. J Seismol. https://doi.org/10.1007/s10950-019-09901-7

Carannante S, D'Alema E, Augliera P, Franceschina G (2020) Improvement of microseismic monitoring at the gas storage concession "Minerbio Stoccaggio" (Bologna, Northern Italy). J Seismol. https://doi.org/10.1007/s10950-01909879-2

De Landro G, Picozzi M, Russo G, Adinolfi GM, Zollo A (2020) Seismic networks layout optimization for a high-resolution monitoring of induced micro-seismicity. J Seismol. https://doi.org/10.1007/s10950-019-09880-9
Lanzoni A, Moratto L, Priolo E, Romano MA (2020) Fast Mw estimation of microearthquakes recorded around the underground gas storage in the Montello-Collalto area (southeastern Alps, Italy). J Seismol. https://doi.org/10.1007/s10950019-09889-0

Skoumal RJ, Brudzinski MR, Currie BS, Ries R (2020) Temporal patterns of induced seismicity in Oklahoma revealed from multi-station template matching. J Seismol. https://doi. org/10.1007/s10950-019-09864-9

Telesca L, Kadirov F, Yetirmishli G, Safarov R, Babayev G, Islamova S, Kazimova S (2020) Analysis of the relationship between water level temporal changes and seismicity in the Mingechevir reservoir (Azerbaijan). J Seismol. https://doi. org/10.1007/s10950-020-09926-3

Publisher's note Springer Nature remains neutral with regard to jurisdictional claims in published maps and institutional affiliations. 